\title{
TOPSIS Method for Supporting the Selection and Ranking of Phase Change Materials for a Latent Heat Storage
}

\author{
J. Basakayi \\ Wind Energy Research Laboratory (WERL) \\ Université du Québec à Rimouski \\ Québec, Canada
}

\author{
A. Ilinca \\ Wind Energy Research Laboratory (WERL) \\ Université du Québec à Rimouski \\ Québec, Canada
}

\begin{abstract}
Compared to sensible heat storage systems, Phase change materials (PCMs) offer many advantages due to their ability to absorb and liberate large quantities of heat without significant temperature change. For a specific application, an appropriate PCM must be selected among several potential candidates. This selection process is not always simple task. An appropriate and logic method must be applied to select a better material. TOPSIS is one of the methods that can be used to make a best selection of PCM: It considers the fact that some criteria must be maximized such as latent heat, thermal conductivity and density. At the other hand, certain numbers of criteria must be minimized (the cost of the PCM, the super cooling degree of PCM). Different steps applied to TOPSIS is highlighted to a selection and ranking of phase change materials. In addition, Tryptych software is used for a sensibility analysis. A case study was considered to demonstrate the application of the methodology.
\end{abstract}

Keywords-TOPSIS, phase change material, AHP, latent heat storage, sensitivity analysis

\section{INTRODUCTION}

Phase change materials are applied in several applications in the fields of engineering: precise thermal control of instruments, thermal storage, food transportation, vaccines and clothing... Generally, these applications can be categorized into two groups: a thermal protection (inertia) and a storage [2].

The materials used into a latent heat storage system are called Phase change materials (PCMs). These PCMs offer many advantages compared to sensible heat storages: A possibility to store large amounts of heat at nearly constant temperature (they have a high energy density); smoothing of temperature variations during the change phase. In addition, the comparison between latent and sensible heat storage reveals that using latent heat storage, storage densities typically 5 to 10 times higher can be reached. PCM storage volume is two times smaller than that of water [1], [3].

During the design process of a latent heat storage unit, an appropriate PCM must be selected. PCM selection is a complex process. This storage material should fulfill certain number of criteria: thermo-physical, kinetics and chemical, economic properties to achieve a better thermal performance of the system: Melting temperature in the desired operating temperature range; High latent heat of fusion; High specific heat; High thermal conductivity; Small volume changes on phase transformation and small vapor pressure at operating temperatures; Congruent melting of the PCM ; High nucleation rate ; High rate of crystal growth; Complete reversible freeze / melt cycle; No degradation after a large number of freeze / melt cycles; Non-corrosiveness to the construction materials; Non-toxic, non-flammable, and nonexplosive materials for safety; low cost and large-scale availability [1],[4-5]. But there is no perfect PCM since not a single material has all the desirable properties to the degree that would be ideal [4].

In order to carry on with a selection process, a material selection methodology that is logic and consistent should be applied. The objective of using such a material selection methodology is to support the decision frequently made in uncertainty and in the awareness that multiple conflicting criteria need to be managed and satisfied. It does therefore seek out the optimum choice of materials throughout a combination of certain key factors [6].

Rastogi et al. applied Multiple Criteria Decision Making (MCDM) approach for ranking and selecting PCMs for domestic HVAC application. Ashby approach has been considered for determining two novel figure of merits (FOM) to grade PCMs performance. Furthermore, the FOMs obtained were subjected to Pareto Optimality test. Finally, the graded materials were ranked using Technique for Order Preference by Similarity to Ideal Solution (TOPSIS). The relative weights for the different criteria were calculated using Shannon's entropy method [7].

$\mathrm{Xu}$ et al. in [8] have suggested a systematic selection procedure of PCMs for a latent heat thermal energy storage (LHTES) in a solar air conditioning system. Pre-screening, ranking and objective function examination based on multicriteria decision making (MCDM) tools were applied. Results show that the proposed approach can serve as an efficient tool in the LHTES design process.

Kumar proposed two multi attribute ways like AHP (analytic hierarchy process) and TOPSIS (Technique for Order of Preference by Similarity to Ideal Solution) for ranking of the 
chosen materials. In this study, same weights were considered for the criteria [9].

To select an optimal PCM, Wang et al., employed the VIKOR method. Stearic acid was determined to be the optimal PCM among the candidates for low-temperature thermal energy storage [11].

Khare et al. made use of a materials selection software based on multi-objective optimization methodology to identify potential PCM media for thermal energy storage. The results show that metals are highly suitable as PCMs for the duty considered (steam from $400-750^{\circ} \mathrm{C}$ ) [12].

The aim of this paper work is to demonstrate a methodology for selecting an appropriate PCM. The following steps are required for this methodology: 1 . Pre-screen the potential PCMs; 2 . Use the AHP to weight the criteria or attributes; 3. Ranking of alternative PCMs by TOPSIS; 4. Use a sensitivity analysis with Triptych software to understand how the final results would have changed if the weights of the criteria would have been different. A case study is considered for an application regarding the selection of a PCM for a latent heat storage.

\section{METHODOLOGY}

\section{A. Pre screeing of the potential PCMs}

Many categories of PCMs can be found in literature. A decision maker has to select an appropriate PCM for a given application. To proceed on the selection process, a melting point in the desired operating temperature must be the first criterion that has to be considered. It should be below the temperature of the heat source and has to match the application to assure the energy storage.

Once the PCMs are selected as potential candidates with their properties such as latent heat capacity, density, specific heat, thermal conductivity... the next step is to exclude all the PCMs having missing data.

\section{B. Evaluation of the weight criteria}

Analytic Hierarchy Process (AHP) will be used to determine the weight of different attributes that are considered. The most used criteria for PCM selection are latent heat capacity, density, specific heat, thermal conductivity and cost.

AHP was developed by Saaty in 1980. It is a multi-criteria decision-making method. The steps to be followed in order to apply AHP are [13]:

Step 1: A decision matrix and derive priorities (weights) for the criteria must be constructed: Different criteria chosen for the application are compared pairwise with respect to the desired goal in order to derive their weight. A check of the consistency of judgments must be done.

To build a matrix, each entry of this matrix is based on Saaty's nine-point scale presented in Table 1. In addition, the comparison matrix depends on the decision maker's judgment concerning the relative importance of different criteria. The criterion in row $\mathrm{i}(\mathrm{i}=1,2 \ldots \mathrm{n})$ is ranked relative to each of the criteria represented by the $n$ columns.
$\mathrm{G}$ forms the evaluation matrix $(\mathrm{n} \times \mathrm{n})$ obtained from the pairwise comparison. For a given element from the matrix $G$, $\mathrm{g}_{\mathrm{ij}}(\mathrm{i}, \mathrm{j}=1,2 \ldots \mathrm{n})$ shows the relative importance of criterion $\mathrm{i}$ respecting criterion $\mathrm{j}$. It has to be noted that when a criterion is compared with itself; for example, density to density, the input entry in the matrix is always assigned the value 1. Therefore, the main diagonal entries of the pair-wise comparison matrix are all 1.

\section{TABLE 1 PREFERENCE SCALE OF PAIR WISE COMPARISON [13]}

\begin{tabular}{|c|c|}
\hline Intensity of relative importance & Definition \\
\hline 1 & Equally important \\
\hline 3 & Moderately important \\
\hline 5 & Strongly important \\
\hline 7 & Very strongly important \\
\hline 9 & Extremely important \\
\hline $2,4,6,8$ & $\begin{array}{c}\text { Intermediate judgment between two } \\
\text { adjacent judgements }\end{array}$ \\
\hline
\end{tabular}

Step 2: Normalization of the matrix by dividing each entry from the column of the pairwise comparison matrix by its column sum.

Step 3: Evaluate the average each row of the normalized matrix. These row averages form the relative weight wi( $i$ $=1,2$..n) of alternative preferences respecting each criterion.

Step 4: Verification of the level of consistency. If $w$ is the column vector of the relative weight, comparison matrix $G$ is consistent if: $\mathrm{G} . \mathrm{W}=\mathrm{n} . \mathrm{W}$

Matrix $\mathrm{X}$ is a n-dimensional column vector. It represents the weight sum of each alternative considered separately and considering each criterion:

$\mathrm{G}:=\left(\begin{array}{cccc}1 & \mathrm{~g}_{12} & \ldots & \mathrm{g}_{1 \mathrm{n}} \\ \mathrm{g}_{21} & 1 & \ldots . & \mathrm{g}_{2 \mathrm{n}} \\ \ldots & \ldots & \ldots & \ldots \\ \mathrm{g}_{\mathrm{n} 1} & \mathrm{~g}_{\mathrm{n} 2} & \cdots & 1\end{array}\right)$

$$
\begin{aligned}
& \mathrm{g}_{\mathrm{ij}} \neq 0 \quad \text { and } \mathrm{g}_{\mathrm{ji}}=\frac{1}{\mathrm{~g}_{\mathrm{ij}}} \\
& \mathrm{X}:=\mathrm{G} \cdot \mathrm{W}=\left(\begin{array}{cccc}
1 & \mathrm{~g}_{12} & \ldots & \mathrm{g}_{1 \mathrm{n}} \\
\mathrm{g}_{21} & 1 & \ldots & \mathrm{g}_{2 \mathrm{n}} \\
\ldots & \ldots & \ldots & \ldots . . \\
\mathrm{g}_{\mathrm{n} 1} & \mathrm{~g}_{\mathrm{n} 2} & \ldots . . & 1
\end{array}\right) \cdot\left(\begin{array}{c}
\mathrm{w}_{1} \\
\mathrm{w}_{2} \\
\ldots \\
\mathrm{w}_{\mathrm{n}}
\end{array}\right)=\left(\begin{array}{c}
\mathrm{c}_{1} \\
\mathrm{c}_{2} \\
\ldots \\
\mathrm{c}_{\mathrm{n}}
\end{array}\right)
\end{aligned}
$$


Step 5: Evaluation of the consistency values $(\mathrm{CV})$ for the cluster of alternatives It is represented by the vector:

$C V_{i}=\frac{c_{i}}{w_{i}}$

Step 6: Calculation of the eigenvalue $\lambda_{\max }$ :

$$
\lambda_{\max }=\frac{\sum_{i=1}^{i=n} C V_{i}}{n}
$$

Where $\mathrm{n}$ is the number of compared elements.

Step 7: Calculation of the consistency index (CI). It should be noted that the quality of the out of the AHP method is strictly related to the consistency of the pair wise comparison judgements:

$$
C I=\frac{\left(\lambda_{\max }-n\right)}{n-1}
$$

Step 8: Use the random inconsistency (RI) index from Table 2 below:

\section{TABLE 2: RANDOM INCONSISTENCY INDEX FOR DIFFERENT MATRIX SIZES [13], [22]:}

\begin{tabular}{|c|c|c|c|c|c|c|c|c|c|c|}
\hline $\begin{array}{c}\text { Matrix } \\
\text { size(n) }\end{array}$ & 1 & 2 & 3 & 4 & 5 & 6 & 7 & 8 & 9 & 10 \\
\hline RI & 0.00 & 0.00 & 0.58 & 0.9 & 1.12 & 1.24 & 1.32 & 1.41 & 1.45 & 1.49 \\
\hline
\end{tabular}

Step 9: Determination the consistency ratio (CR) defined as:

$C R=\frac{C I}{R I}$

CR should be $<0.1$ for the degree of comparison consistency to be acceptable. If $\mathrm{CR}$ is greater than 0.1 , the evaluation procedure has to be repeated to improve consistency ratio.

\section{Evaluation of alternative by TOPSIS}

TOPSIS stands for Technique for Order of Preference by Similarity to Ideal Solution. It is classified as a multi-criteria decision analysis method. Hwang and Yoon developed this method in 1981 [14-15]. Furthermore, TOPSIS has been applied satisfactorily across different applications: Supply Chain Management and Logistics, Design, Engineering and Manufacturing Systems, Business and Marketing Management, Health, Safety and Environment Management,
Human Resources Management, Energy Management, Chemical Engineering, Water Resources Management [16].

The principle behind TOPSIS is that the selected alternative should be as close to the ideal solution as possible and as far from the negative-ideal solution as possible. The ideal solution is derived as a composite of the best performance values exhibited (in the decision matrix) by any alternative for each attribute. The negative-ideal solution consists of the composite of the worst performance values [21-22].

The following inputs are needed in order to apply the TOPSIS method are:

- $\quad m$ alternatives, $n$ criteria and the score of each alternative with respect to each criterion.

If $\mathrm{x}_{\mathrm{ij}}$ is the score of option $\mathrm{i}$ with respect to criterion $\mathrm{j}$, therefore the following matrix is obtained:

$$
\mathrm{X}=(\underset{\mathrm{ij}}{\mathrm{x}}) \quad \mathrm{m} \times \mathrm{n} \text { matrix. }
$$

And $\mathrm{J}$ consists of a set of benefit attributes or criteria (more is better) and $\mathbf{J}$ forms a set of negative attributes or criteria (less is better)

The TOPSIS method is based on the following five computation steps [16]:

Step 1: Gathering the performances of the alternatives on the different criteria and normalization of decision matrix.

Normalize scores from the following expression:

$$
r_{i j}=\frac{x_{i j}}{\left(\sum_{i} x_{i j}^{2}\right)} \quad \text { for } \mathrm{i}=1, \ldots, \mathrm{m} ; \mathrm{j}=1, \ldots, \mathrm{n}
$$

Where $r_{i j}$ and $x_{i j}$ are respectively the normalized and the original scores of decision matrix.

Step 2: Construction of the weighted normalized decision matrix.

Consider a set of weights for each criteria $w_{i}$ for $j=1 \ldots n$.

each column of the normalized decision matrix will be multiplied by its associated weight.

An element of the new matrix is obtained:

$$
V_{i j}=w_{j} r_{i j}
$$

Step 3: Evaluation of the positive ideal solution (PIS) and negative ideal solution (NIS).

-Positive ideal solution (PIS): $A^{*}=\left\{v_{1}^{*}, \ldots v_{n}^{*}\right\}$

where $v_{j}^{*}=\left\{\max _{\mathrm{i}}\left(\mathrm{v}_{\mathrm{ij}}\right)\right.$ if $\mathrm{j} \in \mathrm{J} ; \min _{\mathrm{i}}\left(\mathrm{v}_{\mathrm{ij}}\right)$ if $\left.\epsilon \mathrm{J}^{\prime}\right\}$ 
-Negative ideal solution (NIS): $A^{\prime}=\left\{v_{1}^{\prime}, \ldots v_{n}^{\prime}\right\}$

where $\quad v_{j}^{\prime}=\left\{\min _{i}\left(v_{i j}\right)\right.$ if $j \in J$; $\operatorname{maxi}\left(v_{i j}\right)$ if $\left.j \in J^{\prime}\right\}$

Step 4: Calculation of the separation measures for each alternative.

The separation from the ideal alternative is calculated from:

$$
S_{i}^{*}=\left[\sum_{j}\left(v_{j}^{*}-v_{i j}\right)^{2}\right]^{\frac{1}{2}} \text { for } \mathrm{i}=1 \ldots . \mathrm{m}
$$

Similarly, the separation from the negative ideal alternative is evaluated from:

$$
S_{i}^{\prime}=\left[\sum_{j}\left(v_{j}^{\prime}-v_{i j}\right)^{2}\right]^{\frac{1}{2}} \text { for } \mathrm{i}=1 \ldots \mathrm{m}
$$

Step 5: Evaluation of the relative closeness to the ideal solution $C_{i}^{*}$ :

$$
C_{i}^{*}=\frac{S_{i}^{\prime}}{\left(S_{i}^{*}+S_{i}^{\prime}\right)} \quad \text { with } 0 \prec C_{i}^{*} \prec 1
$$

Step 6: Based on the decreasing values of closeness coefficient obtained, alternatives are ranked from the most valuable to worst.

\section{Sensitivity analysis}

Since the final priority will be strongly influenced by the weights given to the respective criteria, it is useful to perform a "what-if" analysis to see how the results would have changed if the weights of the criteria would have been different [13].

Therefore, different scenario must be considered, and the priorities analysed.

A software called Triptych allows to implement the TOPSIS method and enables a to make a sensitivity analysis.

Triptych is the informational engine of the SDI Tools suite that defines the opportunity for product development by translating abstract customer requirements to concrete design requirements. Triptych processes information that is entered in special Excel worksheets and the results become a key part of the product development process [23].

Some of the capabilities of Triptych are: Requirements tools such as AHP. TOPSIS is one of the design tools used in Triptych.
The methodology applied for sensitivity analysis is summarized in three levels:

- 1 . Use Triptych software to evaluate the ranking of different selected alternatives with to the weight obtained using AHP and compare the result with those obtained from the TOPSIS method

- 2. Change the weight for the attribute in the range in Triptych and assess the ranking in comparison to the result obtained in step 1 . And evaluate that the total of the weight is always 100 .

- 3. Suggest a better choice of PCM.

\section{CASE STUDY}

A case study is considered to demonstrate the methodology. A problem consists of selecting an appropriate phase change material (PCM) and ranking all the selected alternatives that could be found in the literature for a specific application. This PCM will be suitable for a latent heat storage used for an absorption refrigeration machine. A PCM with a melting point in the range of 100 to $120^{\circ} \mathrm{C}$ is suitable for a latent heat storage with a reference to ammonia-refrigeration absorption refrigeration cycle. As shown on Fig.1, an absorption refrigeration machine needs a heat source to operate.

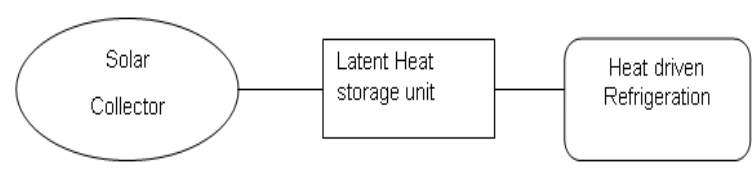

Fig.1: Schematic of integrated solar latent heat storage system for the absorption refrigeration machine

If solar energy is used to power this refrigeration machine, it is relevant to have a thermal storage that could be utilized during night time or when the sun does not shin.

For this case, the following criteria are considered: latent heat capacity, density, specific heat, thermal conductivity and cost.

From different literatures, the following alternatives or options are identified (Table 2): 
TABLE 2: SELECTED ALTERNATIVES

\begin{tabular}{|c|c|c|c|c|c|c|c|}
\hline PCI type & $\mathbb{M P}[\mathrm{C}]$ & If $[\mathrm{kJ} / \mathrm{kg}]$ & $D\left[\mathrm{~kg} / \mathrm{m}^{3}\right.$. & $S H[K J / K g, K]$ & IC $[\mathrm{W} / \mathrm{m}, \mathrm{K}]$ & $C\left[E / m^{3}\right]$ & References \\
\hline Oxalic acid & 105 & 356 & 1900 & 1.62 & $0.134^{a}$ & 524 & {$[17],[18]$} \\
\hline Erythritol & 117 & 340 & 1450 & 2,25 & 0.73 & 1287 & {$[17]$} \\
\hline Oxalic acid Dihydrate & 105 & 264 & 1653 & 2.11 & 0.90 & 339 & {$[17]$} \\
\hline Magnesium Chloride Hexahydrate & 117 & 150 & 1570 & 2,00 & 0.70 & 56 & {$[17]$} \\
\hline Urea- $-\mathrm{NH}_{4} \mathrm{Cl}$ & 102 & 214 & 1348 & 1.77 & 0.76 & 174 & {$[17]$} \\
\hline Urea- $\mathrm{K}_{2} \mathrm{CO}_{3}$ & 102 & 206 & 1415 & 1.66 & 0.78 & 269 & {$[17]$} \\
\hline Urea- $\mathrm{KNO}_{3}$ & 109 & 195 & 1416 & 1.66 & 0.81 & 255 & {$[17]$} \\
\hline Urea-NaCl & 112 & 230 & 1372 & 1.72 & 0.82 & 180 & {$[17]$} \\
\hline Urea-KCl & 115 & 227 & 1370 & 1.69 & 0.83 & 197 & {$[17]$} \\
\hline
\end{tabular}

In Table 2, MP is the melting point, $\mathrm{LH}$ is the latent heat capacity, D is the density, $\mathrm{SH}$ is the specific heat, TC is the thermal conductivity and $\mathrm{C}$ is the cost with their respective SI unit.

\section{RESULTS AND DISCUSSIONS}

Table 3 provides the decision matrix of different criteria which are latent heat, density, specific heat, thermal conductivity and cost.

TABLE 3: DECISION MATRIC OF CRITERIA

\begin{tabular}{|c|c|c|c|c|c|}
\hline & L.H & $\mathrm{D}$ & $\mathrm{SH}$ & TC & C \\
\hline 导 & 1 & 9 & 7 & 5 & 5 \\
\hline$\boxminus$ & 0.111 & 1 & 3 & 0.333 & 1 \\
\hline$\frac{T}{\Omega}$ & 0.143 & 0.333 & 1 & 0.2 & 1 \\
\hline$\vec{\Omega}$ & 0.2 & 3 & 5 & 1 & 1 \\
\hline$\Omega$ & 0.2 & 1 & 1 & 1 & 1 \\
\hline
\end{tabular}

From Table 3, Latent heat capacity is considered extremely important than density criteria. Therefore 9 means that value 9 is of relative importance for latent heat $(\mathrm{LH})$ compared with Density (D) (i.e. $\mathrm{g}_{12}=9$ ) and the value $1 / 9$ is of relative importance for density (D) compared with latent heat (LH) (i.e. $\mathrm{g}_{21}=1 / 9$ ).

$$
a+b=\gamma
$$

Note that the equation is centered

TABLE 4: NORMALIZED MATRIX FROM PAIR WISE COMPARISON OF CRITERIA

\begin{tabular}{|c|c|c|c|c|c|c|c|c|c|c|}
\hline & HH & HC & $\pi$ & $l$ & $W_{i}$ & G & $\mathrm{CV}_{i}$ & 0 & Rl & CR \\
\hline Hh & 0.605 & 0.412 & 0.6604 & 0.556 & 0.573 & 3.111 & 5,104 & & & \\
\hline 0 & 0.067 & 0.176 & OONA & 0111 & 0.0.9A & 0.498 & 5294 & & & \\
\hline $\mathrm{HC}$ & 0.086 & 0,059 & 0.027 & 0111 & 0.061 & 0,308 & 5.1049 & 0,101 & 111 & O.N9 \\
\hline$\pi$ & 0,121 & 0.294 & 0.133 & 0111 & 0.1714 & 0.975 & 5,001 & & & \\
\hline$l$ & 0,121 & 0,559 & 0.133 & 0111 & 0.099 & 0.543 & 5.481 & & & \\
\hline
\end{tabular}

Step 2 to 9 for TOPSIS method is summarized in Table 4: a normalized matrix is obtained, and the relative weight is evaluated. And finally, the level of consistency is checked. $\mathrm{w}_{\mathrm{i}}$ represents the relative weight of each criterion. Latent heat capacity is the dominant criterion with $57.3 \%$. Thermal conductivity is the second with $17.4 \%$. Cost, density and heat capacity are respectively the third, fourth and fifth place.

The consistency ratio $\mathrm{CR}$ is $0.09<0.1$. The level of consistency is acceptable. 
TABLE 5: DECISION MATRIX

\begin{tabular}{|c|c|c|c|c|c|}
\hline & LH & D & SH & TC & C \\
\hline Alt 1 & 9 & 9 & 5 & 3 & 2 \\
\hline Alt 2 & 8 & 5 & 6 & 7 & 1 \\
\hline Alt 3 & 7 & 7 & 6 & 8 & 3 \\
\hline Alt 4 & 6 & 5 & 5 & 8 & 6 \\
\hline Alt 5 & 6 & 3 & 5 & 7 & 6 \\
\hline Alt 6 & 5 & 4 & 5 & 7 & 4 \\
\hline Alt 7 & 5 & 2 & 5 & 7 & 7 \\
\hline Alt 8 & 4 & 4 & 5 & 8 & 5 \\
\hline Alt 9 & 2 & 3 & 6 & 7 & 9 \\
\hline
\end{tabular}

Alt 1 = Oxalic acid; Alt $2=$ Erythritol; Alt $3=$ Oxalic acid Dihydrate; Alt $4=$ Urea- $\mathrm{NaCl}$; Alt $5=$ Urea $-\mathrm{KCl}$; Alt $6=$ Urea $-\mathrm{K} 2 \mathrm{CO} 3$; Alt 7 = Urea- NH4Cl; Alt 8 = Urea $-\mathrm{KNO} 3$; Alt 9 = Magnesium chloride.

9 alternatives (options) and 5 attributes/criteria and the score of each option with respect to each criterion is available in this matrix (Table 5).

TABLE 6: FIRST STEP FOR NORMALIZATION OF DECISION MATRIX

\begin{tabular}{|c|c|c|c|c|c|}
\hline & LH & D & SH & TC & C \\
\hline Alt 1 & 81 & 81 & 25 & 9 & 4 \\
\hline Alt 2 & 64 & 25 & 36 & 49 & 1 \\
\hline Alt 3 & 49 & 49 & 36 & 64 & 9 \\
\hline Alt 4 & 36 & 25 & 25 & 64 & 36 \\
\hline Alt 5 & 36 & 9 & 25 & 49 & 36 \\
\hline Alt 6 & 25 & 16 & 25 & 49 & 16 \\
\hline Alt 7 & 25 & 4 & 25 & 49 & 49 \\
\hline Alt 8 & 16 & 16 & 25 & 64 & 25 \\
\hline Alt 9 & 4 & 9 & 36 & 49 & 81 \\
\hline$\Sigma \mathrm{x}_{\mathrm{ij}}^{2}$ & 336 & 234 & 258 & 446 & 257 \\
\hline$\left(\Sigma \mathrm{x}_{\mathrm{ij}}^{2}\right)^{1 / 2}$ & 18,3303 & 15,29706 & 16,06238 & 21,11871 & 16,03122 \\
\hline
\end{tabular}

Table 6 is the first step for the normalization of decision matrix. The last two rows show respectively the sum of the squared of each entry in a given column and the square root of the results obtained in the previous row.
The next step is the normalization of the decision matrix.

TABLE 7: NORMALIZATION OF THE DECISION MATRIX

\begin{tabular}{|r|c|r|r|r|r|}
\hline & \multicolumn{1}{|c|}{ LH } & \multicolumn{1}{c|}{ D } & \multicolumn{1}{c|}{ SH } & TC & \multicolumn{1}{c|}{ C } \\
\hline Alt 1 & 0,49099 & 0,588348 & 0,311286 & 0,142054 & 0,124757 \\
\hline Alt 2 & 0,436436 & 0,32686 & 0,373544 & 0,343203 & 0,062378 \\
\hline Alt 3 & 0,381881 & 0,457604 & 0,373544 & 0,392232 & 0,187135 \\
\hline Alt 4 & 0,327327 & 0,32686 & 0,311286 & 0,392232 & 0,37427 \\
\hline Alt 5 & 0,327327 & 0,196116 & 0,311286 & 0,343203 & 0,37427 \\
\hline Alt 6 & 0,272772 & 0,261488 & 0,311286 & 0,343203 & 0,249513 \\
\hline Alt 7 & 0,272772 & 0,130744 & 0,311286 & 0,343203 & 0,436648 \\
\hline Alt 8 & 0,218218 & 0,261488 & 0,311286 & 0,392232 & 0,311891 \\
\hline Alt 9 & 0,109109 & 0,196116 & 0,373544 & 0,343203 & 0,561405 \\
\hline
\end{tabular}

Table 7 , in order to normalize each entry of decision matrix is $2 \quad 1 / 2$

divided by $(\Sigma x \quad$ ) to get $r$

This is done by using equation [1].

Multiply each column of the normalized decision matrix by its associated weight in Table 8 by using equation [2].

TABLE 8: WEIGHTED NORMALIZED DECISION MATRIX

\begin{tabular}{|c|r|r|r|c|c|}
\hline \multicolumn{1}{c|}{} & LH & \multicolumn{1}{c|}{ D } & SH & TC & C \\
\hline Alt 1 & 0,281337 & 0,055305 & 0,018988 & 0,024717 & 0,012351 \\
\hline Alt 2 & 0,250078 & 0,030725 & 0,022786 & 0,059717 & 0,006175 \\
\hline Alt 3 & 0,218818 & 0,043015 & 0,022786 & 0,068248 & 0,018526 \\
\hline Alt 4 & 0,187558 & 0,030725 & 0,018988 & 0,068248 & 0,037053 \\
\hline Alt 5 & 0,187558 & 0,018435 & 0,018988 & 0,059717 & 0,037053 \\
\hline Alt 6 & 0,156299 & 0,02458 & 0,018988 & 0,059717 & 0,024702 \\
\hline Alt 7 & 0,156299 & 0,01229 & 0,018988 & 0,059717 & 0,043228 \\
\hline Alt 8 & 0,125039 & 0,02458 & 0,018988 & 0,068248 & 0,030877 \\
\hline Alt 9 & 0,062519 & 0,018435 & 0,022786 & 0,059717 & 0,055579 \\
\hline
\end{tabular}

Determine the ideal and negative ideal solutions

Positive ideal solution (PIS):

$A^{*}=\{0.281337 ; 0.055305 ; 0.022786 ; 0.006175\}$

Negative ideal solution (NIS):

$A^{\prime}=\{0.062956 ; 0.01229 ; 0.018988 ; 0.024717 ; 0.055579\}$

Determine separation from ideal solution 
TABLE 9: SEPARATION FROM THE POSITIVE IDEAL ALTERNATIVE

\begin{tabular}{|r|r|r|c|c|c|c|r|}
\hline & \multicolumn{1}{|c|}{ LH } & \multicolumn{1}{c|}{ D } & SH & TC & C & $\sum\left(\mathrm{v}^{*}{ }_{\mathrm{j}} \mathrm{v}_{\mathrm{ij}}\right)^{2}$ & $\left(\sum\left(\mathrm{v}_{\mathrm{j}} \mathrm{v}_{\mathrm{ij}}\right)^{2}\right)^{1 / 2}$ \\
\hline Alt 1 & \multicolumn{1}{|c}{,09E-13 } & $6,511 \mathrm{E}-14$ & $1,44212 \mathrm{E}-05$ & 0,001895 & $3,81417 \mathrm{E}-05$ & 0,001947474 & 0,044130199 \\
\hline Alt 2 & 0,000871 & 0,000604183 & $2,63897 \mathrm{E}-14$ & $7,28 \mathrm{E}-05$ & $2,02638 \mathrm{E}-13$ & 0,001548003 & 0,039344668 \\
\hline Alt 3 & 0,00372 & 0,000151049 & $2,63897 \mathrm{E}-14$ & $1,67 \mathrm{E}-13$ & 0,000152556 & 0,004023562 & 0,063431554 \\
\hline Alt 4 & 0,008551 & 0,000604183 & $1,44212 \mathrm{E}-05$ & $1,67 \mathrm{E}-13$ & 0,000953432 & 0,010122625 & 0,100611255 \\
\hline Alt 5 & 0,008551 & 0,001359403 & $1,44212 \mathrm{E}-05$ & $7,28 \mathrm{E}-05$ & 0,000953432 & 0,010950616 & 0,104645192 \\
\hline Alt 6 & 0,015363 & 0,000944033 & $1,44212 \mathrm{E}-05$ & $7,28 \mathrm{E}-05$ & 0,000343242 & 0,016737407 & 0,12937313 \\
\hline Alt 7 & 0,015363 & 0,001850295 & $1,44212 \mathrm{E}-05$ & $7,28 \mathrm{E}-05$ & 0,001372936 & 0,018673363 & 0,136650514 \\
\hline Alt 8 & 0,024157 & 0,000944033 & $1,44212 \mathrm{E}-05$ & $1,67 \mathrm{E}-13$ & 0,000610201 & 0,025725666 & 0,160392225 \\
\hline Alt 9 & 0,04769 & 0,001359403 & $2,63897 \mathrm{E}-14$ & $7,28 \mathrm{E}-05$ & 0,00244076 & 0,051563253 & 0,227075434 \\
\hline
\end{tabular}

In Table 9, the separation from the ideal alternative is evaluated in the last column.

Determine separation from negative ideal solution $\mathrm{S}$

TABLE 10: SEPARATION FROM NEGATIVE IDEAL SOLUTION

\begin{tabular}{|r|r|r|r|r|r|r|r|}
\hline & \multicolumn{1}{|c|}{ LH } & \multicolumn{1}{c|}{ D } & \multicolumn{1}{c|}{ SH } & \multicolumn{1}{c|}{ TC } & \multicolumn{1}{c|}{ C } & $\Sigma\left(\mathrm{v}_{j}^{\prime}-\mathrm{v}_{\mathrm{ij}}\right)^{2}$ & $\left(\Sigma\left(\mathrm{v}_{\mathrm{j}}^{\prime}-\mathrm{v}_{\mathrm{ij}}\right)^{2}\right)^{1 / 2}$ \\
\hline Alt 1 & 0,04769 & 0,00185 & $2,19687 \mathrm{E}-13$ & $1,7541 \mathrm{E}-13$ & 0,001869 & 0,051409 & 0,226736406 \\
\hline Alt 2 & 0,035671 & 0,00034 & $1,4426 \mathrm{E}-05$ & 0,001225025 & 0,002441 & 0,039691 & 0,199225832 \\
\hline Alt 3 & 0,024771 & 0,000944 & $1,4426 \mathrm{E}-05$ & 0,001894984 & 0,001373 & 0,028998 & 0,17028738 \\
\hline Alt 4 & 0,015854 & 0,00034 & $2,19687 \mathrm{E}-13$ & 0,001894984 & 0,000343 & 0,018432 & 0,135763712 \\
\hline Alt 5 & 0,015854 & $3,78 \mathrm{E}-05$ & $2,19687 \mathrm{E}-13$ & 0,001225025 & 0,000343 & 0,01746 & 0,132135321 \\
\hline Alt 6 & 0,008918 & 0,000151 & $2,19687 \mathrm{E}-13$ & 0,001225025 & 0,000953 & 0,011247 & 0,106052757 \\
\hline Alt 7 & 0,008918 & $3,22 \mathrm{E}-15$ & $2,19687 \mathrm{E}-13$ & 0,001225025 & 0,000153 & 0,010295 & 0,101465698 \\
\hline Alt 8 & 0,003963 & 0,000151 & $2,19687 \mathrm{E}-13$ & 0,001894984 & 0,00061 & 0,00662 & 0,081361088 \\
\hline Alt 9 & $1,67 \mathrm{E}-14$ & $3,78 \mathrm{E}-05$ & $1,4426 \mathrm{E}-05$ & 0,001225025 & $2,64 \mathrm{E}-15$ & 0,001277 & 0,035738089 \\
\hline
\end{tabular}

In Table 10, the separation from the negative alternative is evaluated in the last column.

Calculate the relative closeness to the ideal solution using equation [7].

TABLE 11: RELATIVE CLOSENESS TO THE IDEAL SOLUTION

\begin{tabular}{|c|c|c|}
\cline { 2 - 3 } & $\mathrm{C}^{*}{ }_{\mathrm{i}}$ & Ranking \\
\hline Alt 1 & 0,837078 & 1 \\
\hline Alt 2 & 0,835082 & 2 \\
\hline Alt 3 & 0,728599 & 3 \\
\hline Alt 4 & 0,574357 & 4 \\
\hline Alt 5 & 0,55805 & 5 \\
\hline Alt 6 & 0,450472 & 6 \\
\hline Alt 7 & 0,426118 & 7 \\
\hline Alt 8 & 0,336546 & 8 \\
\hline Alt 9 & 0,135983 & 9 \\
\hline
\end{tabular}

Ranking of alternatives-TOPSIS METHOD

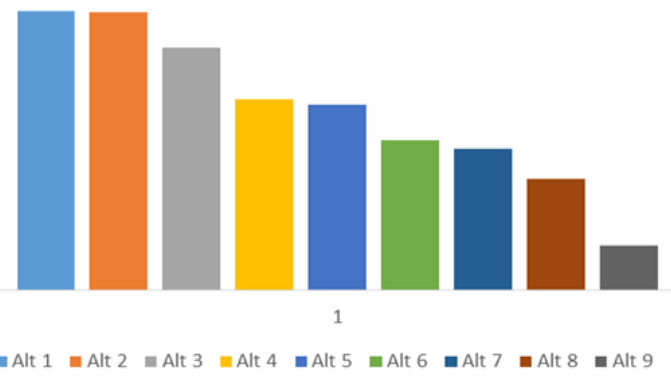

Fig.2 Ranking of alternatives - TOPSIS method 
Based on this result provided on Table 11 and Fig.2, Oxalic acid is the best candidate PCM. It is follows by 2. Erythritol, 3. Oxalic acid dehydrate; 4. Urea- $\mathrm{NaCl} ; 5$. Urea- $\mathrm{KCl}$;

6. Urea- $\mathrm{K}_{2} \mathrm{CO}_{3} ; 7$. Urea- $\mathrm{NH}_{4} \mathrm{Cl} ; 8$. Urea- $\mathrm{KNO}_{3}$, 9. Magnesium chloride.

From the evaluation done previously using TOPSIS method, the dominant criterion is latent heat with $57.3 \%$. If the local weight is changed, how does it affect the ranking?

Triptych software for the sensitivity analysis. And the following scenario are considered:
1. Compare the results from TOPSIS and Triptych.

2. All the criteria with the same weight;

3. Cost has $57.3 \%$ of the total weight;

4. Thermal conductivity has $57.3 \%$ of the total weight;

5. Density has $57.3 \%$ of the total weight;

6. Specific heat has $57.3 \%$ of the total weight.

7. Slightly change of the criteria weight from the AHP result

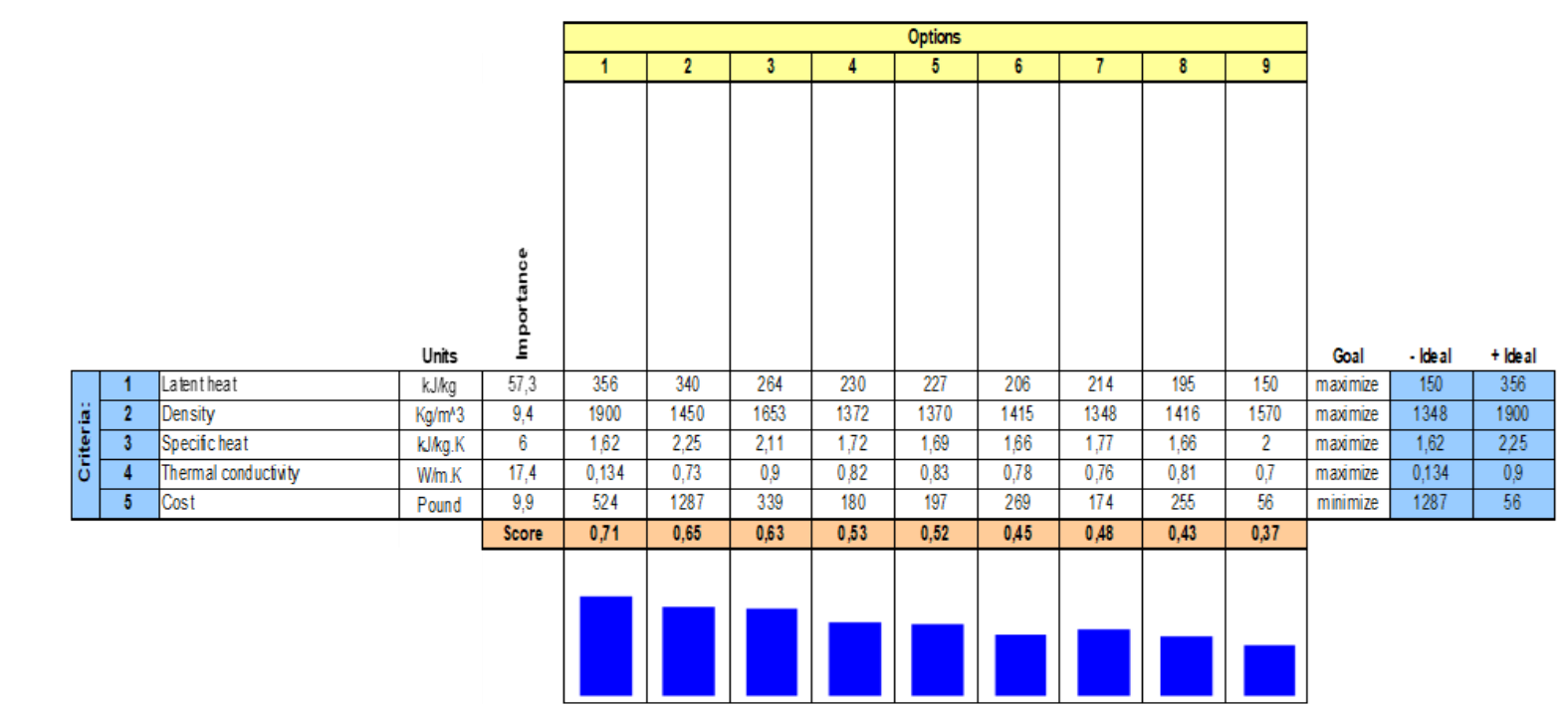

Fig.3 Results considering the weight criteria obtained for TOPSIS method

In Fig.3, the entries are the properties as it was identified in literature. The software exports the results for the weight criteria from AHP requirements and a goal must be specified. Latent heat, specific heat, density, thermal conductivity must be maximised, and cost must be minimised. At the bottom, a ranking is obtained. Results are closely the same as obtained for TOPSIS method in Table 11. Only exception is between AL 7 and AL 8 that change the rank.

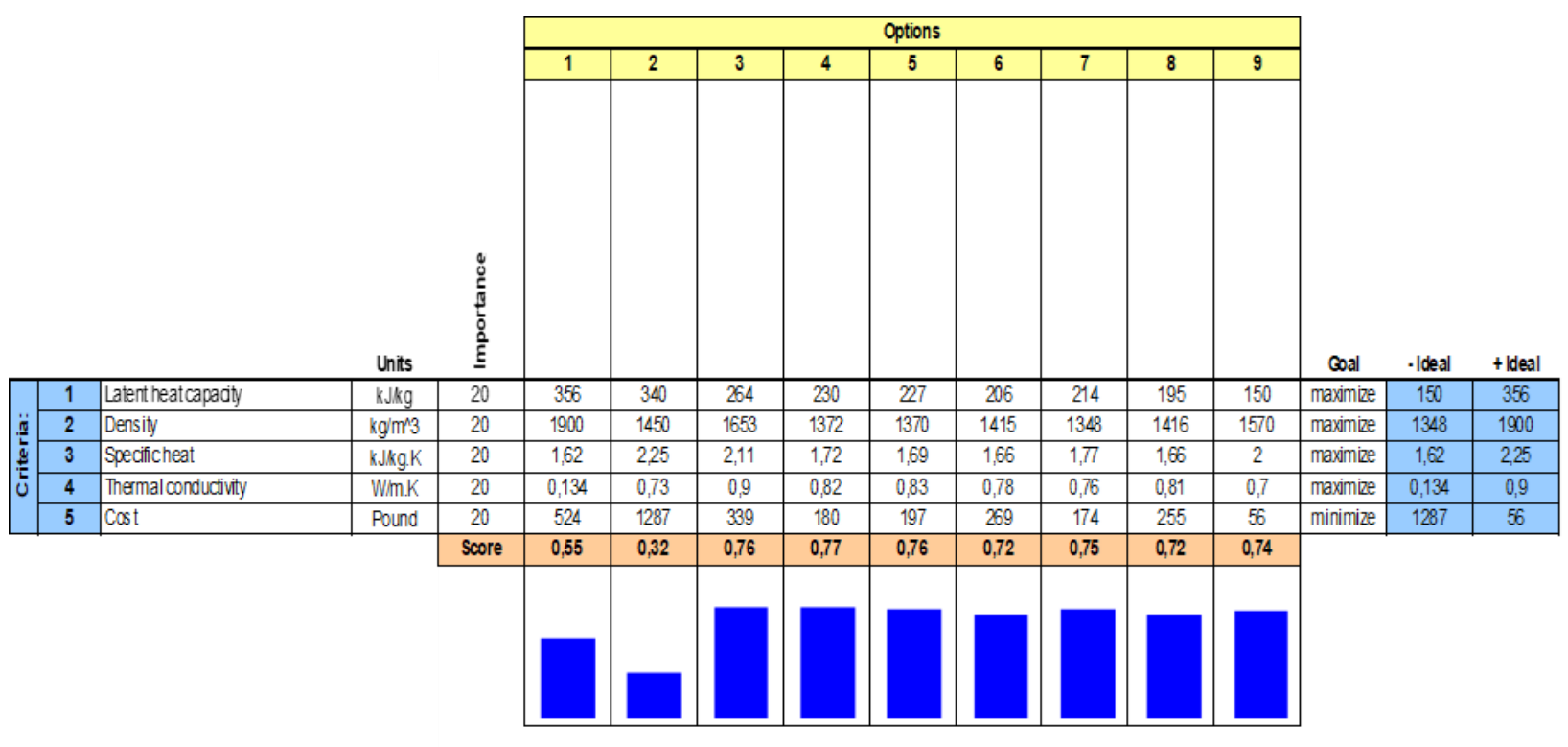

Fig.4 Results considering the same weight criteria 
In Fig.4, if the same weight is considered for all the criteria, Urea- $\mathrm{NaCl}$ becomes the best candidate PCM follows by oxalic acid dehydrate and Urea-KCl.

In the same way, if cost is considered as the dominant criterion, it shows that Magnesium chloride is the best choice PCM and erythritol is the worst candidate PCM.

Oxalic acid dehydrate is the best choice if the dominant criterion is the thermal conductivity.

When density is considered as the dominant criterion weight, oxalic acid dehydrate is the best choice.

Oxalic acid is the best choice if specific heat weight is the dominant criterion.

As overall result, Oxalic acid will be the best candidate PCM to be recommended for the latent heat storage.

\section{CONCLUSION}

A selection of PCM for a given application is not simple task. TOPSIS method was considered in this research paper to select an appropriate PCM for a given application and rank all the alternatives or options. Different steps that must be followed to use this method were explained. A software called Triptych serves to do the sensitivity analysis. A case study showing the application of the methodology was considered to demonstrate how to use the methodology.

TOPSIS and Triptych can be used as a proper tool for the selection of an appropriate and ranking of PCM.

\section{REFERENCES}

[1] Sharma, S. D., \& Sagara, K. (2005). Latent heat storage materials and systems: a review. International Journal of Green Energy, 2(1), $1-56$.

[2] Zalba, B., Marín, J. M., Cabeza, L. F., \& Mehling, H. (2003). Review on thermal energy storage with phase change: materials, heat transfer analysis and applications. Applied thermal engineering, 23(3), 251-283.

[3] Fleischer, A. S. (2015). Thermal energy storage using phase change materials: Fundamentals and applications. Springer.

[4] Hale D.V; Hoover M.J., O'Neill (1971): PCM Handbook. NASA. Alabama.

[5] Basakayi, J. (2012). Modelling and design of a latent heat thermal storage system with reference to solar absorption refrigeration (Master dissertation, University of Johannesburg).

[6] D’Errico, F. (2015). Material Selections by a Hybrid Multi-Criteria Approach. Springer.

[7] Rastogi, M., Chauhan, A., Vaish, R., \& Kishan, A. (2015). Selection and performance assessment of Phase Change Materials for heating, ventilation and air-conditioning applications. Energy Conversion and Management, 89, 260-269.

[8] Xu, H; Sze,J.Y; Romagnoli, A.; Py, X.(2017). Selection of Phase Change Material for Thermal Energy Storage in Solar Air Conditioning Systems. Energy Procedia, 1054281 - 4288.

[9] Kumar, R. S. latent heat storage material evaluation base on AHP and TOPSIS for low temperature solar heating applications. International Journal of Mechanical and Production Engineering Research and Development Vol. 5, Issue 1, 2015, 7382.

[10] Karim, R., \& Karmaker, C. L. (2016). Machine selection by AHP and TOPSIS methods. American Journal of Industrial Engineering, 4(1), 7-13.
[11] Wang, Yi; Zhang, Yu; Yang, Weihua; Ji, Hui (2015): Selection of Low-Temperature Phase-Change Materials for Thermal Energy Storage Based on the VIKOR Method. In Energy Technology 3 (1), pp. 84-89. DOI: 10.1002/ente.201402098.

[12] Khare, S., Dell'Amico, M., Knight, C., \& McGarry, S. (2012) Selection of materials for high temperature latent heat energy storage. Solar energy materials and solar cells, 107, 20-27.

[13] Mu, E., \& Pereyra-Rojas, M. (2016). Practical Decision Making: An Introduction to the Analytic Hierarchy Process (AHP) Using Super Decisions (Vol. 2). Springer.

[14] https://en.wikipedia.org/wiki/TOPSIS retrived 14, December 2017

[15] Behzadian, M., Otaghsara, S. K., Yazdani, M., \& Ignatius, J. (2012). A state-of the-art survey of TOPSIS applications. Expert Systems with Applications, 39(17), 13051-13069.

[16] Behzadian, M., Otaghsara, S. K., Yazdani, M., \& Ignatius, J. (2012) A state-of the-art survey of TOPSIS applications. Expert Systems with Applications, 39(17), 13051-13069.

[17] Da Cunha, J. P., \& Eames, P. (2016). Thermal energy storage for low and medium temperature applications using phase change materials-a review. Applied Energy, 177, 227-238.

[18] https://comptox.epa.gov/dashboard/dsstoxdb/results?search=DTXSI D0025816, retrieved 14, December 2017

[19] Barreneche, Camila; Navarro, M. Elena; Cabeza, Luisa F. Fernández, A. Inés (2015): New database to select phase change materials. Chemical nature, properties, and applications. Journal of Energy Storage 3, pp. 18-24. DOI: 10.1016/j.est.2015.08.003.

[20] Rastogi, M., Chauhan, A., Vaish, R., \& Kishan, A. (2015). Selection and performance assessment of Phase Change Materials for heating, ventilation and air-conditioning applications. Energy Conversion and Management, 89, 260-269.

[21] Kahraman, C. (Ed.). (2008). Fuzzy multi-criteria decision making: theory and applications with recent developments (Vol. 16) Springer Science \& Business Media.

[22] Jahan, A., Edwards, K. L., \& Bahraminasab, M. (2016). Multicriteria decision analysis for supporting the selection of engineering materials in product design. Butterworth-Heinemann.

[23] http://www.stat-design.com/Software/TOPSIS.html retrieved 5, January 2018. 